\title{
Protective Role of Peroxiredoxin I in Heat-Killed Staphylococcus Aureus-infected Mice
}

\author{
HU-NAN SUN ${ }^{1,2 *}$, YUE LIU ${ }^{1 *}$, JIAN-NAN WANG $^{1}$, CHUANG WANG $^{1}$, REN LIU $^{2}$, LING-ZU KONG $^{2}$, \\ XING ZHEN ${ }^{2}$, NISANSALA CHANDIMALI ${ }^{2}$, YU-DONG CUI ${ }^{1}$, SUN-UK KIM $^{3}$, DONG-SEOK LEE ${ }^{4}$, \\ DAE-YEUL YU ${ }^{5}$, JI-SU KIM ${ }^{6}$, DONG KEE JEONG ${ }^{2}$, TAEHO KWON ${ }^{6}$ and YING-HAO HAN ${ }^{1}$ \\ ${ }^{1}$ College of Life Science \& Technology, Heilongjiang Bayi Agricultural University, Daqing, P.R. China; \\ ${ }^{2}$ Laboratory of Animal Genetic Engineering and Stem Cell Biology, \\ Advanced Convergence Technology and Science, Jeju National University, Jeju, Republic of Korea; \\ ${ }^{3}$ Futuristic Animal Resource \& Research Center, \\ Korea Research Institute of Bioscience and Biotechnology, Chungcheongbuk-do, Republic of Korea; \\ ${ }^{4}$ School of Life Sciences, KNU Creative Bio Research Group, \\ Kyungpook National University, Daegu, Republic of Korea; \\ ${ }^{5}$ Disease Model Research Laboratory, Genome Editing Research Center, \\ Korea Research Institute of Bioscience and Biotechnology, Daejeon, Republic of Korea; \\ ${ }^{6}$ Primate Resources Center, Korea Research Institute of Bioscience and Biotechnology, Jeonbuk, Republic of Korea
}

\begin{abstract}
Background/Aim: Staphylococcus aureus (S. aureus) is a major gram-positive pathogen, which can cause toxic and immunogenic injuries both in nosocomial and community-acquired infections. Peroxiredoxin (Prx) I plays crucial roles in cellular apoptosis, proliferation, and signal transduction as well as in immunoregulation. The present study aimed to investigate whether Prx I protects mice from death caused by the heat-killed Staphylococcus aureus. Materials and Methods: In the present study, we challenged the wild-type and Prx I-deficient mice with heat-killed S. aureus (HKSA). The effects of Prx I were evaluated by a series
\end{abstract}

This article is freely accessible online.

\footnotetext{
*These Authors contributed equally to this work.

Correspondence to: Hu-Nan Sun, College of Life Science \& Technology, Heilongjiang Bayi Agricultural University, Xinyanglu, 163319, Daqing, P.R. China. Tel: +86 4596819300, Fax: +86 4596819295, e-mail: sunmkbb@qq.com or Taeho Kwon, Primate Resources Center, Korea Research Institute of Bioscience and Biotechnology (KRIBB), 351-33 Neongme-gil, Ibam-myeon, Jeongeup-si, Jeonbuk, 56216, Republic of Korea. Tel: +82 635705316, Fax: +82 635705309, e-mail: kwon@kribb.re.kr or Ying-Hao Han, College of Life Science \& Technology, Heilongjiang Bayi Agricultural University, Xinyanglu, 163319, Daqing, P.R. China. Tel: +86 4596819300, Fax: +86 4596819295, e-mail: hyh1211@qq.com
}

Key Words: Peroxiredoxin I, Staphylococcus aureus, intraperitoneal, inflammatory, knockout. of in vitro and in vivo experiments including western blot, Haematoxylin and Eosin staining, splenocyte analysis and cytokines analysis. Results: Intra-peritoneal (ip) inoculation of HKSA resulted in increased mortality of Prx I-knockout (KO) mice with severe liver damage and highly populated spleens with lymphocytes. Furthermore, HKSA infections also bursted the production of both pro-inflammatory and antiinflammatory serum cytokines in Prx I KO compared to wildtype mice. Conclusion: Enhanced mortality of S. aureusinfected mice with Prx I deficiency suggested that Prx I may protect against the infection-associated lethality of mice.

Peroxiredoxin (Prx) I, an antioxidant enzyme, belongs to 2-cysteine Prxs (1). Recent evidence shows that Prx I participates in several cellular signaling pathways by interacting with diver proteins to regulate cell differentiation, apoptosis and proliferation (2-4). Accumulation of reactive oxygen species (ROS) in cells can cause oxidation of DNA, membrane lipids and proteins, resulting in increased cellular damage (5). Prx I plays an important role in scavenging ROS in cells (6). In the last decade, the regulatory role of Prx I in tumorigenesis has been well defined both in vivo and in vitro. Depletion of Prx I can spontaneously induce the development of several malignant cancers and severe haemolytic anaemia, as well as oxidative DNA damage and decreased cell proliferation (7). Furthermore, a previous study by our group has also shown that Prx I suppresses the $\mathrm{K}$-ras-induced lung carcinogenesis via the ROS/ERK/cyclin D1 signaling pathway (8), suggesting that Prx I may be a tumor suppressor that could prevent carcinogenesis. 
Apart from its anti-cancer properties, the immune regulatory roles of Prx I was recently considered.by Riddell et al., who reported that recombinant Prx I stimulates the secretion of pro-inflammatory cytokines, such as TNF- $\alpha$ and IL- 6 in macrophages, by binding to toll like receptor 4 (TLR-4) (9). Furthermore, knockdown of Prx I modulates the balance of IL-10, IL- $1 \beta$ and TNF- $\alpha$ secretion in lipopolysaccharide (LPS)-stimulated RAW264.7 macrophage cells (10). In a previous study we have also shown that mouse deficiency of Prx I attenuates the phagocytic activity of macrophages in clearing damaged red blood cells (11). These findings suggest that Prx I possibly plays key roles as an immunoregulator both in vivo and in vitro.

Staphylococcus aureus ( $S$. aureus) is a major grampositive pathogen present in both nosocomial and community-acquired infections (12). There is a great number of secreted proteins and cell-wall associated factors in $S$. aureus that can cause toxic and immunogenic responses (13, 14). Furthermore, it has also been reported that heat-killed $S$. aureus (HKSA) infection can cause septic shock in mice, through the activation of the TLR2- signalling pathway (12, 15). Thus, HKSA is often used as a sepsis mouse model in experimental studies.

In the present study, we investigated the role of Prx I in initiating an immune response and cytokine production, as well as in the viability of $S$. aureus infected mice. Intraperitoneal (ip) inoculation of HKSA resulted in increased death of Prx I knockout (KO) mice with severe liver damage, immune reactions, and increased production of cytokines and apoptosis in the liver. This study aimed to investigate the protective role of PRX I against $S$. aureus-induced lethality in mice .

\section{Materials and Methods}

Mice and genotypic analysis. The Prx I KO mice used in the experiments were generated by heterozygous mice, and the genotype was confirmed by PCR and western blotting (16) (Figure 1A). C57BL/6J $(n=12)$ and Prx I KO mice $(n=12)$ pathogen-free mice used for the heat-killed Staphylococcus aureus (HKSA) challenge were at 8-10 weeks of age. Their survival was carefully observed for 4 days. All animals were housed in microisolator cages with laminar air flow under ambient light. S. aureus strain Wood 46 (ATCC 10832) was kindly provided by the laboratory of Professor Yu-Dong Cui (College of Life Science \& Technology, Heilongjiang Bayi Agricultural University). HKSA was diluted in sterile PBS [approximately $2.6 \times 10^{11}$ colony-formation units $(\mathrm{CFU}) / \mathrm{ml}$ ] and was injected intra-peritoneally (ip) to the animals. The primers used for the mouse genotype analysis are as follows: i) for the Neo gene: forward primer 5'-gcttgggtggagaggctattcg-3'; reverse primer 5'gtaaagcacgaggaagcggtcagcc-3' and ii) for the Prx I gene: forward primer 5'-ctggaaacctggcagtgata-3'; reverse primer 5'-ctgtgactgata gaagattggt-3'. The Institutional Animal Care and Use Committee approved the both animal care and experiments.
Cytokines analysis. Serum and tissue (liver and lungs) were collected from HKSA treated wild type and Prx I KO mice at the following times: i) 0 hours, ii) 36 hours, iii) 48 hours and iv) $60 \mathrm{~h}$, Tissues were minced and lysed in a protein lysis buffer (150 mM NaCl, $1 \%$ Nonidet p-40, $50 \mathrm{mM}$ Tris, $\mathrm{pH}$ 8.0) containing protein inhibitor (cOmplete ${ }^{\mathrm{TM}}$, Mini, EDTA-free, Merck, NJ, USA). The lysis mixtures were then centrifuged and the supernatants were extracted. The levels of cytokines (IL-6 and IL-10) were detected using ELISA (R\&D Systems, Minneapolis, USA), according to manufacturer's instructions. The absorbance at $540 \mathrm{~nm}$ was measured using a UV MAX kinetic microplate reader (Molecular Devices, Menlo Park, CA).

Haematoxylin and eosin staining. To understand the pathological changes following HKSA infection, the livers and lungs were collected from wild type and Prx I KO mice at the indicated times following HKSA injections. Tissues were harvested after removing the blood by heart perfusion and fixation with perfused heparinized saline containing $3.7 \%$ formaldehyde through the left ventricle. The tissue sections ( $4 \mu \mathrm{M}$ in thickness) were stained with haematoxylin and eosin (H\&E) and were observed under a microscope (Olympus IX70 Fluorescence Microscope, Olympus, Japan). The experiments were performed with 10 wild type and 10 Prx I KO mice.

Splenocyte isolation and analysis. To assess the effect of HKSA infection on mice on lymphocyte distribution, spleens from wild type and Prx I KO mice were collected following HKSA infection at indicated times. The splenocytes were obtained using the spleen lymphocyte cell separation medium kit (Solarbio Life Sciences, P.R. China), according to the manufacturer's instructions. Subsequently, cells were stained with anti-CD4-FITC, anti-CD8-PE, anti-CD25PE, anti-CD11b-PE and anti-NK1.1-PE antibodies (Santa Cruz, USA) for 30 minutes at $4^{\circ} \mathrm{C}$ in cold FACs buffer (1X PBS and $1 \%$ FBS). The cytotoxic $\mathrm{T}$ cells (CD8 positive), regulatory $\mathrm{T}$ cells (CD4/CD25 positive), monocytes (CD11b positive) and NK (NK1.1 positive) were analysed using flow cytometry (BD FACS Calibur, CA, USA) and the numbers of the cells were presented on a histogram.

Western blot analysis. Tissue protein lysates obtained from wild type and Prx I KO mice following HKSA injection were separated in $12 \%$ sodium dodecyl sulphate (SDS)-polyacrylamide gels and were transferred onto nitrocellulose (NC) membranes (Millipore, Bedford, MA, USA). The membranes were blotted with primary antibodies against Prx I, cleaved caspase-3, Bcl-2 (Santa Cruz, USA), and $\beta$-actin (Sigma-Aldrich, St. Louis, USA) at $4^{\circ} \mathrm{C}$ overnight. Following washing of the membranes with tris-buffered saline (TBS) [10 mM Tris- $\mathrm{HCl}(\mathrm{pH} 7.5), 150 \mathrm{mM} \mathrm{NaCl}]$ and $0.2 \%$ Tween 20, the membranes were incubated with horseradish peroxidase (HRP)-conjugated goat anti-rabbit IgG (Sigma-Aldrich) or anti-mouse $\operatorname{IgG}$ (Merck) for 1 hour at room temperature (RT). The specific binding was detected using a chemiluminescence detection system (Amersham, Berkshire, UK), according to the manufacturer's instructions.

Statistical analysis. The data are depicted as a mean \pm SEM. Student's $t$-tests were performed using the GraphPad Prism 4.0 software (GraphPad Software Inc., San Diego, CA, USA), and $p<0.05$ was considered as indicative of significant difference. 
A

(a)
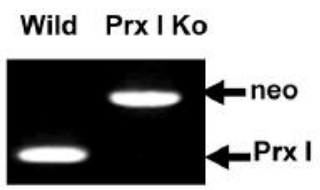

(b)



B



Figure 1. Prx I deficiency increases the HKSA induced mortality in mice. (A) (Upper Panel) PCR analysis of genomic DNA isolated from wild-type (lane 1) and Prx I homozygous knockout mice (lane 2). The $700 \mathrm{bp}$ (Neo) and $250 \mathrm{bp}$ (Prx I) arrows indicate the PCR products of Prx I KO and wild-type mice, respectively. (Lower Panel) Western blot analysis of Prx I expression in the liver from wild and Prx I KO mice. (B) The wild (n=12) and Prx I KO (n=12) mice were ip injected with (approximately $2.85 \times 10^{10}$ CFU/mouse) HKSA, and mortality was observed at the indicated times. No additional mice died 96 h following the injection. HSKA: Heat-killed Staphylococcus aureus; PRX I KO: peroxiredoxin I knockout; h: hours.

A

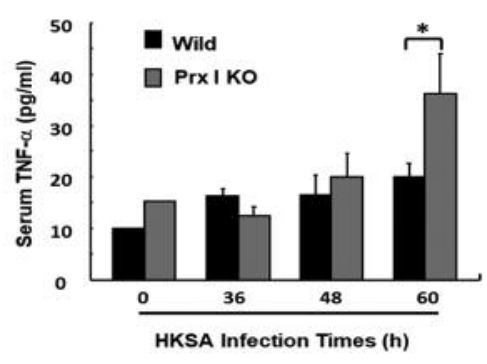

D



G

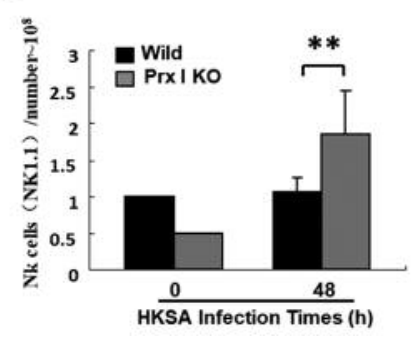

B

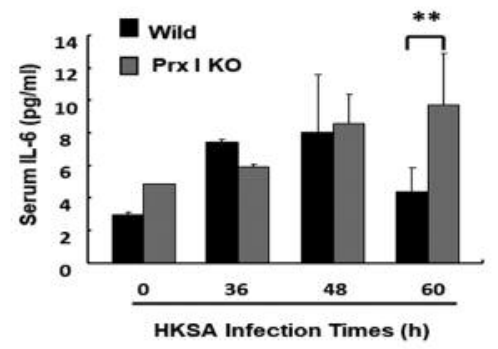

$\mathbf{E}$



C

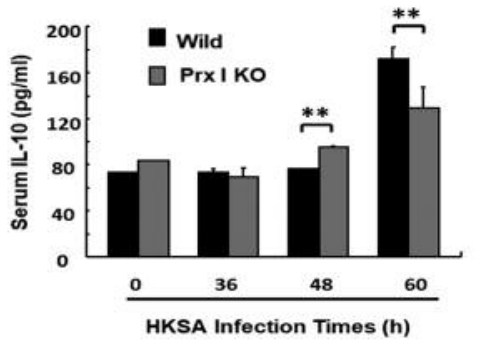

$\mathbf{F}$



Figure 2. Impaired production of cytokines and immune cells in HKSA-infected Prx I KO mice. (A) Wild type (n=10) and Prx I KO mice (n=10) were challenged with HKSA (approximately $2.85 \times 10^{10} \mathrm{CFU} /$ mouse) at indicated times. The serum TNF- $\alpha,(B) I L-6$ and $(C) I L-10$ were detected using ELISA. (D) The wild-type and Prx I KO mice were challenged with HKSA (approximately $2.85 \times 10^{10}$ CFU/mouse) at indicated times and the splenocytes were collected for analysis of immune cell distribution. The number of CD8-positive T cells, CD4/CD25 positive, (E) Treg, (F) CD11b positive monocytes and $(G)$ NK1.1 positive NK cells were analyzed using flow cytometry. $n=6, * p<0.05, * * p<0.01$. HSKA: Heat-killed Staphylococcus aureus; PRX I KO: peroxiredoxin I knockout; h: hours. 
A

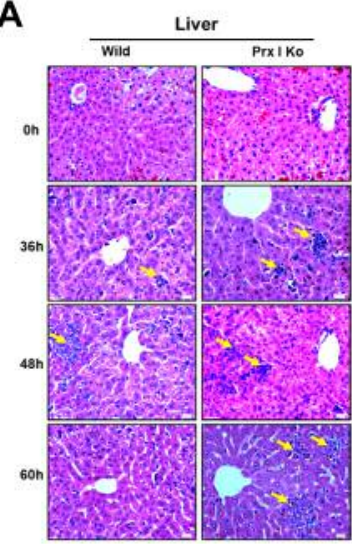

B

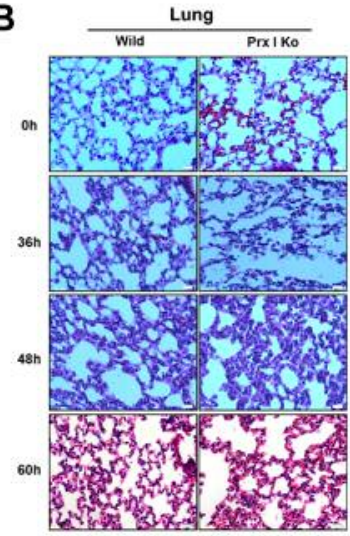

C

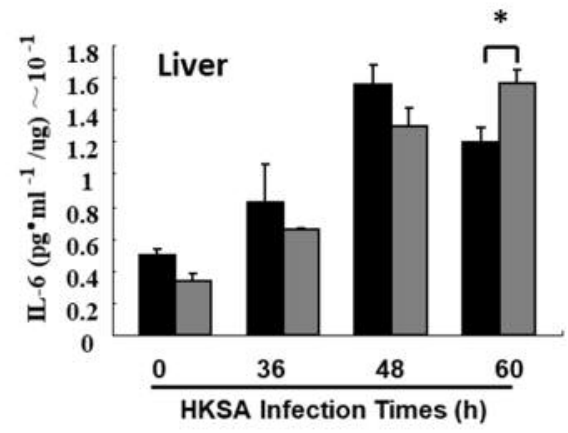

E

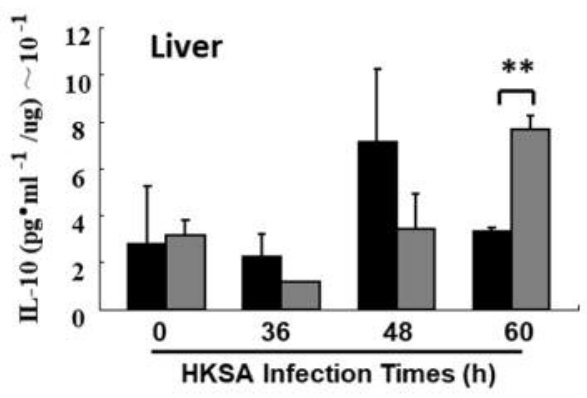

D

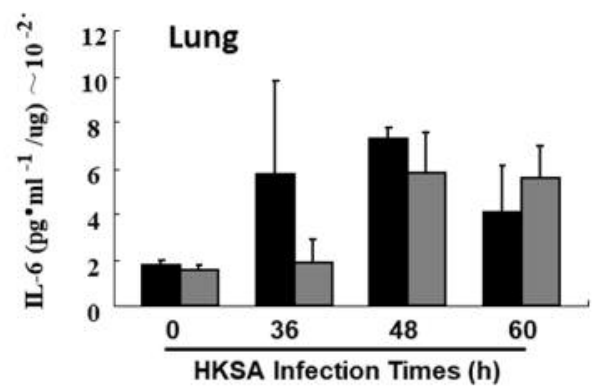

$\mathbf{F}$

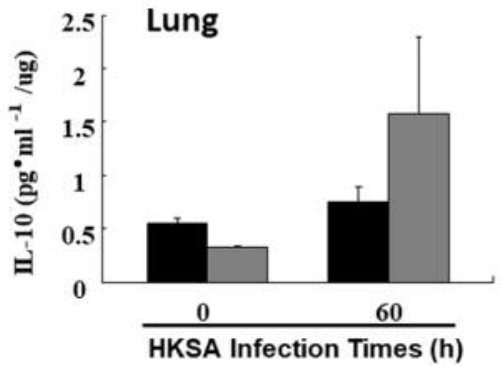

Figure 3. Severe liver inflammation and increased tissue cytokines in Prx I KO mice in response to HKSA infection. (A, B) The H\&E-stained sections from wild type and Prx I KO mice at the indicated times (0,36, 48 and $60 \mathrm{~h})$ following the HKSA infection, microscope images at 400X show signs of immune cell infiltration in the liver (A) (yellow arrow, immune cell infiltration) and (B) lungs. $n=6$ (C-F) The cytokine levels IL-6 and IL-10 were analysed in the liver and lung of wild type and Prx I KO mice at the indicated times following the HKSA infection. The produced levels of cytokines are represented as $\mathrm{pg} / \mathrm{mg}$ of total protein, $(n=6$ for each experiment) $* p<0.05$, ** $p<0.01$.

\section{Results}

Prx I deficiency increased the HKSA-induced mortality in mice. To examine the possible protective role of Prx I against the $S$. aureus infection, wild type $(\mathrm{n}=12)$ and Prx I KO mice $(n=12)$ were challenged with HKSA injections and their survival was observed for 4 days. The results show that deficiency of Prx I increased their susceptibility to succumb to HKSA infection compared with wild type mice (Figure 1B).

Impaired production of cytokines and immune cells in HKSAinfected Prx I KO mice. To examine the effect of $S$. aureus infection on cytokine responses, wild type $(\mathrm{n}=10)$ and Prx I KO mice $(n=10)$ were challenged with HKSA injections as previously at indicated times. Interestingly, we observed that the production of the pro-inflammatory cytokines, such as IL-6 increased in Prx I KO mice while the anti-inflammatory cytokine IL-10 compared to wild type mice infected with HKSA (Figure 2A-C).

The results from our splenocytes' analysis of immune cells' distribution showed that the $\mathrm{CD}^{+}{ }^{+} \mathrm{T}$ cells, $\mathrm{CD} 11 \mathrm{~b}^{+}$ monocytes, $\mathrm{NK} 1.1^{+} \mathrm{NK}$ cells and $\mathrm{CD} 4^{+} / \mathrm{CD} 25^{+}$regulatory $\mathrm{T}$ cells were significantly increased in Prx I KO mice compared to wild type mice infected with HKSA (Figure 2D-G).

Severe liver inflammations in Prx I KO mice as a response to HKSA infection. To investigate the histopathological changes following S. aureus infection, the HKSA-challenged liver and lung were collected both from wild type and Prx I KO mice for analysis. Our results show that $S$. aureus increased the invasion of immune cells in liver and lung tissues in both infected wild type and Prx I KO mice. Although there was no difference between wild type and Prx I KO concerning the 
A
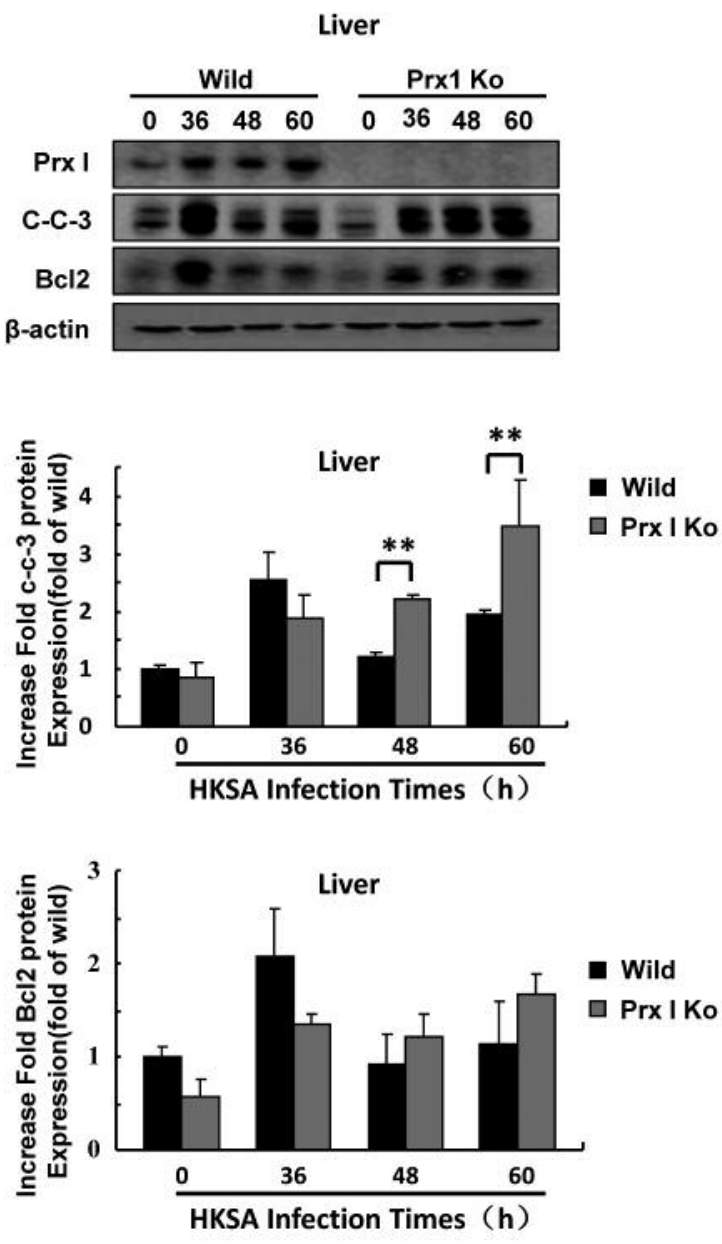

B


Figure 4. Increased apoptosis in the liver of Prx I KO mice in response to HKSA infection. The protein expression levels of cleaved caspase-3 and $B c l-2$ in both liver $(A)$ and lungs $(B)$ of wild type and Prx I KO mice following HKSA infection. The protein expression levels are presented as means $\pm S D(C-F)$. ( $n=6$ for each experiment $) * p<0.05$ and $* * p<0.01$.

lungs, a severe inflammatory response was observed in the liver of Prx I KO mice compared to the liver of wild type mice (Figure 3A and B). Furthermore, IL-6 and IL-10 production was also significantly higher in the liver of Prx I KO mice compared to wild type mice (Figure 3C-F), but not in the lungs, suggesting that the liver of Prx I KO mice were the ones most affected by the $S$. aureus infection.

Increased liver apoptosis in Prx I KO mice as a response to HKSA infection. To assess whether tissue inflammation and increased cytokine production led to increased hepatocyte or lung epithelial apoptosis we assessed the expression of certain apoptosis-related proteins in these tissues. Our results show that cleaved caspase 3 protein expression was upregulated both in the liver and lungs of Prx I KO mice compared to wild type mice, however, there was no significant difference in $\mathrm{Bcl} 2$ protein expression levels between wild type and Prx I KO mice following HKSA infection (Figure 4A and B).

\section{Discussion}

In the present study, we analyzed the regulatory function of Prx I on both lethal shock reaction and host immune response to $S$. aureus infection in mice. Several studies have previously shown that $S$. aureus promotes a host immune response from minor skin infections to severe systemic inflammations, including septic lethal shock $(17,18)$. TLR2 is known as a key molecule to contribute to host immune response against $S$. aureus infections $(19,20)$, and deletion of TLR2 increases the mortality of mice during $S$. aureus infection $(15,21-23)$ combined with impaired cytokines 
production and severe inflammatory burden. Similarly, in this study, Prx I KO mice showed an enhanced susceptibility to $S$. aureus infection within four days post-infection as well as impaired production of cytokines in plasma serum, suggesting a possible protective role of $\operatorname{Prx}$ I against $S$. aureus infection. Our previous study has shown that deficiency of Prx I results in increasing lipopolysaccharide (LPS) induced lethal shock in mice (24), which ismainly stimulated through TLR4 dependent signaling. Furthermore, stimulation of RAW264.7 mouse macrophages with LPS could significantly induce Prx I mRNA as well as protein expression in vitro via the Src/PI3k/JNK signaling pathway (25). Moreover, the regulatory function of Prx I on LPSinduced macrophages through TLR4 was also reported recently in vitro $(9,10)$. These findings demonstrate that Prx I plays an essential role in a TLR4-induced host immune response, but the regulatory function of $\operatorname{Prx} I$ in grampositive bacterial infection is not yet understood.

Previous studies have shown that the TNF- $\alpha$ and IL- 6 are considered early cytokines that are induced by $S$. aureus infection (26-28), both in immune and non-immune cells in vivo. In addition, the anti-inflammatory cytokine, IL-10, has been shown to be up-regulated by LR2 signaling initiated by $S$. aureus infection $(29,30)$. Similarly, in our experiments both pro-inflammatory cytokines (TNF- $\alpha$ and IL-6) and antiinflammatory (IL-10) production were higher in the serum of Prx I KO mice compared to wild-type mice following $S$. aureus infection. At the same time, the executive immune cells, such as CD8 positive T cell, monocytes, NK cells and regulatory $\mathrm{T}$ cells were also increased in the spleen of Prx I KO compared to wild type mice. Our results revealed that Prx I deficiency could promote both an innate and an adaptive immune response to $S$. aureus infection, but the possible mechanisms should be further studied.

Liver is a large organ that offers immune surveillance against bacterial infections and can help to clear the entrance of bacteria into bloodstream $(15,31)$. Herein, our results showed an increased invasion of inflammatory cells and higher accumulation of IL-6 and IL-10 in the liver of Prx I KO mice compared to wild type, which led to increased apoptosis through the up-regulation of cleaved caspase 3 . These results suggest that deletion of Prx I increase the susceptibility to $S$. aureus infection in mice and may influence the host liver defense functions against this particular bacterial infection. In conclusion, our findings demonstrate that Prx I deficiency enhances the mortality of mice caused by $S$. aureus infection, and increases the circulating cytokines production as well as the spleen lymphocytes distribution, which lead to severe inflammatory damage in these mice's liver. Additional future studies should provide more clinical data concerning the role of Prx I on $S$. aureus infection so as to provide strategies for its treatment.

\section{Conflicts of Interest}

The Authors declare that there are no conflicts of interest.

\section{Authors' Contributions}

HNS, YL, TK, and YHH. designed and wrote the whole manuscript, HNS, YL, TK, and YHH performed the experiments, CW, RL, LZK, $\mathrm{XZ}, \mathrm{NC}, \mathrm{YDC}, \mathrm{SUK}$, DSL, DYY, JSK, and DKJ contributed in the revision of the manuscript. All authors read and approved the final manuscript.

\section{Acknowledgements}

This research was supported by a Basic Science Research Program through the National Research Foundation of Korea funded by the Ministry of Education (2017R1D1A1B03028188). This study was supported by Grants from the Korean Research Institute of Bioscience and Biotechnology Research Initiative Program (KGM5161914) and OGM5201922.

\section{References}

1 Ding C, Fan X and Wu G: Peroxiredoxin 1 - an antioxidant enzyme in cancer. Journal of cellular and molecular medicine 21(1): 193-202, 2017. PMID: 27653015. DOI: 10.1111/ jcmm.12955

2 Neumann CA, Cao J and Manevich Y: Peroxiredoxin 1 and its role in cell signaling. Cell Cycle 8(24): 4072-4078, 2009. PMID: 19923889. DOI: $10.4161 / \mathrm{cc} .8 .24 .10242$

3 Morinaka A, Funato Y, Uesugi K and Miki H: Oligomeric peroxiredoxin-i is an essential intermediate for $\mathrm{p} 53$ to activate mst1 kinase and apoptosis. Oncogene 30(40): 4208-4218, 2011. PMID: 21516123. DOI: 10.1038/onc.2011.139

4 Jarvis RM, Hughes SM and Ledgerwood EC: Peroxiredoxin 1 functions as a signal peroxidase to receive, transduce, and transmit peroxide signals in mammalian cells. Free Radic Biol Med 53(7): 1522-1530, 2012. PMID: 22902630. DOI: 10.1016/ j.freeradbiomed.2012.08.001

5 Lee SF and Pervaiz S: Assessment of oxidative stress-induced DNA damage by immunoflourescent analysis of 8-oxodg. Methods Cell Biol 103(99-113), 2011. PMID: 21722801 DOI: 10.1016/B978-0-12-385493-3.00005-X

6 Graves JA, Metukuri M, Scott D, Rothermund $\mathrm{K}$ and Prochownik EV: Regulation of reactive oxygen species homeostasis by peroxiredoxins and c-myc. J Biol Chem 284(10): 6520-6529, 2009. PMID: 19098005. DOI: 10.1074/jbc.M8 07564200

7 Neumann CA, Krause DS, Carman CV, Das S, Dubey DP, Abraham JL, Bronson RT, Fujiwara Y, Orkin SH and Van Etten RA: Essential role for the peroxiredoxin prdx 1 in erythrocyte antioxidant defence and tumour suppression. Nature 424(6948): 561-565, 2003. PMID: 12891360. DOI: 10.1038/nature01819

8 Park YH, Kim SU, Lee BK, Kim HS, Song IS, Shin HJ, Han YH, Chang KT, Kim JM, Lee DS, Kim YH, Choi CM, Kim BY and Yu DY: Prx i suppresses k-ras-driven lung tumorigenesis by opposing redox-sensitive erk/cyclin d1 pathway. Antioxid Redox Signal 19(5): 482-496, 2013. PMID: 23186333. DOI: 10.1089/ ars.2011.4421 
9 Riddell JR, Wang XY, Minderman $\mathrm{H}$ and Gollnick SO: Peroxiredoxin 1 stimulates secretion of proinflammatory cytokines by binding to tlr4. J Immunol 184(2): 1022-1030, 2010. PMID: 20018613. DOI: 10.4049/jimmunol.0901945

10 Tae Lim Y, Sup Song D, Joon Won T, Lee YJ, Yoo JS, Eun Hyung $\mathrm{K}$, Won Yoon J, Park SY and Woo Hwang K: Peroxiredoxin-1, a possible target in modulating inflammatory cytokine production in macrophage like cell line raw264.7. Microbiol Immunol 56(6): 411-419, 2012. PMID: 22486405. DOI: $10.1111 / \mathrm{j} .1348-0421.2012 .00453 . \mathrm{x}$

11 Han YH, Kwon T, Kim SU, Ha HL, Lee TH, Kim JM, Jo EK, Kim BY, Yoon DY and Yu DY: Peroxiredoxin i deficiency attenuates phagocytic capacity of macrophage in clearance of the red blood cells damaged by oxidative stress. BMB Rep 45(10): 560-564, 2012. PMID: 23101509. DOI: 10.5483/ bmbrep.2012. 45.10 .082

12 Li B, Li J, Pan X, Ding G, Cao H, Jiang W, Zheng J and Zhou $\mathrm{H}$ : Artesunate protects sepsis model mice challenged with Staphylococcus aureus by decreasing tnf-alpha release via inhibition tlr2 and nod 2 mrna expressions and transcription factor nf-kappab activation. Int Immunopharmacol 10(3): 344350, 2010. PMID: 20005985. DOI: 10.1016/j.intimp.2009. 12.006

13 Cohen J: The immunopathogenesis of sepsis. Nature 420(6917): 885-891, 2002. PMID: 12490963. DOI: 10.1038/nature01326

14 Bronner S, Monteil H and Prevost G: Regulation of virulence determinants in Staphylococcus aureus: Complexity and applications. FEMS Microbiol Rev 28(2): 183-200, 2004. PMID: 15109784. DOI: 10.1016/j.femsre.2003.09.003

15 Yimin, Kohanawa M, Zhao S, Ozaki M, Haga S, Nan G, Kuge $\mathrm{Y}$ and Tamaki N: Contribution of toll-like receptor 2 to the innate response against Staphylococcus aureus infection in mice. PLoS One 8(9): e74287, 2013. PMID: 24058538. DOI: 10.1371/ journal.pone.0074287

16 Park YH, Kim HS, Lee JH, Choi SA, Kim JM, Oh GT, Kang SW, Kim SU and Yu DY: Peroxiredoxin i participates in the protection of reactive oxygen species-mediated cellular senescence. BMB Rep 50(10): 528-533, 2017. PMID: 28893373 DOI: 10.5483/BMBRep.2017.50.10.121

17 Kremserova S and Nauseef WM: Staphylococcus aureus promotes receptor-interacting protein kinase 3- and proteasedependent production of il-1beta in human neutrophils. J Leukoc Biol, 2018. PMID: 30548986. DOI: 10.1002/JLB.4HI0918-346R

18 Wang F, Wang R and Liu H: The acute pulmonary toxicity in mice induced by Staphylococcus aureus, particulate matter, and their combination. Exp Anim, 2018. PMID: 30531117. DOI: 10.1538/expanim.18-0102

19 Silva MT: Macrophage phagocytosis of neutrophils at inflammatory/infectious foci: A cooperative mechanism in the control of infection and infectious inflammation. J Leukoc Biol 89(5): 675-683, 2011. PMID: 21169518. DOI: 10.1189/ jlb.0910536

20 Takeuchi $\mathrm{O}$ and Akira S: Pattern recognition receptors and inflammation. Cell 140(6): 805-820, 2010. PMID: 20303872. DOI: $10.1016 /$ j.cell.2010.01.022

21 Hoebe K, Georgel P, Rutschmann S, Du X, Mudd S, Crozat K, Sovath S, Shamel L, Hartung T, Zahringer U and Beutler B: Cd36 is a sensor of diacylglycerides. Nature 433(7025): 523527, 2005. PMID: 15690042 . DOI: $10.1038 /$ nature03253

22 Takeuchi O, Hoshino K and Akira S: Cutting edge: Tlr2deficient and myd88-deficient mice are highly susceptible to
Staphylococcus aureus infection. J Immunol 165(10): 53925396, 2000. PMID: 11067888. DOI: 10.4049/jimmunol.165. 10.5392

23 Stuart LM, Deng J, Silver JM, Takahashi K, Tseng AA, Hennessy EJ, Ezekowitz RA and Moore KJ: Response to Staphylococcus aureus requires cd36-mediated phagocytosis triggered by the cooh-terminal cytoplasmic domain. J Cell Biol 170(3): 477-485, 2005. PMID: 16061696. DOI: 10.1083/jcb.200 501113

24 Sun HN, Feng L, Wang AG, Wang JY, Liu L, Jin MH, Shen GN, Jin CH, Lee DS, Kwon TH, Cui YD, Yu DY and Han YH: Peroxiredoxin i deficiency increases lpsinduced lethal shock in mice. Mol Med Rep 18(2): 2427-2432, 2018. PMID: 29901182. DOI: $10.3892 / \mathrm{mmr} .2018 .9170$

25 Bast A, Fischer K, Erttmann SF and Walther R: Induction of peroxiredoxin I gene expression by lps involves the src/pi3k/jnk signalling pathway. Biochim Biophys Acta 1799(5-6): 402-410, 2010. PMID: 19941984. DOI: 10.1016/j.bbagrm.2009.11.015

26 Paik YH, Lee KS, Lee HJ, Yang KM, Lee SJ, Lee DK, Han KH, Chon CY, Lee SI, Moon YM and Brenner DA: Hepatic stellate cells primed with cytokines upregulate inflammation in response to peptidoglycan or lipoteichoic acid. Lab Invest $86(7)$ : 676-686, 2006. PMID: 16619004. DOI: 10.1038/labinvest.3700422

27 Jiang W, Li B, Zheng X, Liu X, Cen Y, Li J, Pan X, Cao H, Zheng $\mathrm{J}$ and Zhou H: Artesunate in combination with oxacillin protect sepsis model mice challenged with lethal live methicillinresistant Staphylococcus aureus (mrsa) via its inhibition on proinflammatory cytokines release and enhancement on antibacterial activity of oxacillin. Int Immunopharmacol 11(8): 1065-1073, 2011. PMID: 21396483. DOI: 10.1016/j.intimp. 2011.02.028

28 Mal P, Dutta K, Bandyopadhyay D, Basu A, Khan R and Bishayi B: Azithromycin in combination with riboflavin decreases the severity of Staphylococcus aureus infection induced septic arthritis by modulating the production of free radicals and endogenous cytokines. Inflamm Res 62(3): 259-273, 2013. PMID: 23229721. DOI: 10.1007/s00011-012-0574-z

29 Frodermann V, Chau TA, Sayedyahossein S, Toth JM, Heinrichs DE and Madrenas J: A modulatory interleukin-10 response to staphylococcal peptidoglycan prevents th1/th17 adaptive immunity to Staphylococcus aureus. J Infect Dis 204(2): 253262, 2011. PMID: 21673036. DOI: 10.1093/infdis/jir276

30 Mele T and Madrenas J: Tlr2 signalling: At the crossroads of commensalism, invasive infections and toxic shock syndrome by Staphylococcus aureus. Int J Biochem Cell Biol 42(7): 10661071, 2010. PMID: 20363358. DOI: 10.1016/j.biocel. 2010.03.021

31 Kadhim S, Singh NP, Zumbrun EE, Cui T, Chatterjee S, Hofseth L, Abood A, Nagarkatti P and Nagarkatti M: Resveratrolmediated attenuation of Staphylococcus aureus enterotoxin binduced acute liver injury is associated with regulation of microRNA and induction of myeloid-derived suppressor cells. Front Microbiol 9(2910), 2018. PMID: 30619104. DOI: $10.3389 /$ fmicb. 2018.02910
Received February 27, 2019

Revised April 3, 2019

Accepted April 8, 2019 